Article

\title{
Pedestrian Injury Severity Analysis in Motor Vehicle Crashes in Ohio
}

\author{
Majbah Uddin * (10) and Fahim Ahmed \\ Department of Civil and Environmental Engineering, University of South Carolina, Columbia, SC 29208, USA; \\ ahmedf@cec.sc.edu \\ * Correspondence: muddin@cec.sc.edu; Tel.: +1-803-447-4445
}

Received: 3 April 2018; Accepted: 28 April 2018; Published: 7 May 2018

\begin{abstract}
According to the National Highway Traffic Safety Administration, 116 pedestrians were killed in motor vehicle crashes in Ohio in 2015. However, no study to date has analyzed crashes in Ohio in order to explore the factors contributing to the pedestrian injury severity resulting from motor vehicle crashes. This study fills this gap by investigating the crashes involving pedestrians exclusively in Ohio. This study uses the crash data from the Highway Safety Information System, from 2009 to 2013. The explanatory factors include the pedestrian, driver, vehicle, crash, and roadway characteristics. Both fixed- and random-parameters ordered probit models of injury severity (where possible outcomes are major, minor, and possible/no injury) were estimated. The model results indicate that older pedestrian (65 and over), younger driver (less than 24), driving under influence (DUI), struck by truck, dark-unlighted roadways, six-lane roadways, and speed limits of $40 \mathrm{mph}$ and $50 \mathrm{mph}$ were all factors associated with more severe injuries to the pedestrians. Conversely, older driver (65 and over), passenger car, crash occurring in urban locations, daytime traffic off-peak (10 a.m. to 3:59 p.m.), weekdays, and daylight condition were all factors associated with less severe injuries. This study provides specific safety recommendations so that effective countermeasures can be developed and implemented by policy makers, which in turn will improve overall highway safety.
\end{abstract}

Keywords: pedestrian safety; crash severity; crash factors; ordered probit model; random parameter model

\section{Introduction}

In the United States, 5376 pedestrians were killed and 70,000 were injured in traffic crashes in 2015; this number of fatality is the highest since 1996 [1]. Every $1.6 \mathrm{~h}$ a pedestrian was killed and every $7.5 \mathrm{~min}$ a pedestrian was injured in traffic crashes, on average [1]. These fatalities accounted for about 15 percent of the total fatalities that occurred on highways in the U.S. [2]. According to the National Highway Traffic Safety Administration, 116 pedestrians were killed in motor vehicle crashes in Ohio in 2015 [1]. These large numbers of fatalities and injuries of pedestrians from motor vehicle crashes highlight the necessity of the analysis of such crashes. For this reason, several studies have been undertaken by researchers in the past investigating different crash factors related to pedestrian-vehicle crashes, such as pedestrian, driver, roadway, environmental, vehicle, crash, and land-use characteristics [3-16]. However, no study has analyzed crashes in Ohio in order to explore the factors influencing injury severity of pedestrians. Hence, there is a need to investigate the crashes involving pedestrians exclusively in Ohio.

Numerous research efforts have been published addressing pedestrian safety. The critical aspects of pedestrian-vehicle crash investigation include finding contributing factors, employing a variety of methodological techniques, level of spatial analysis (aggregation or disaggregation), and mitigation strategies. Lee and Abdel-Aty [11] studied vehicle-pedestrian crashes at intersections using 1999 to 
2002 Florida crash data. The study concluded that pedestrian characteristics (e.g., older pedestrian, intoxicated), vehicle type (e.g., larger than passenger car), environment (e.g., dark-lighted condition), and adverse weather were the factors that contributed to injury severity. Pour-Rouholamin and Zhou [14] studied single-vehicle single-pedestrian highway patrol reported crash data from 2010 to 2013 in Illinois. They found that older pedestrian and pedestrian without contrasting cloths, pick-up truck, sport-utility vehicle (SUV), bus, divided highways, multilane highways, dark-unlighted condition, and summer season were the factors contributing to injury severities. Abdul-Aziz et al. [3] studied pedestrian-vehicle crash data (combined from several data sources) from 2002 to 2006 in New York City and conducted a spatially disaggregated borough-based analysis on the built environment. The study found that factors contributing to the injury severities were: roadway characteristics (e.g., number of lanes, grades, light condition, road surface), traffic attributes (e.g., signal control, type of vehicle), and land-use characteristics (e.g., parking facilities, commercial area, industrial area). Kim et al. [9] studied injury severity from single-vehicle single-pedestrian crash data from 1997 to 2000 in North Carolina (NC, USA). The contributing factors found in the study were the age of pedestrian, male and intoxicated drivers, SUV, truck, two-way divided highway, off-roadway, freeway, turning vehicle, speeding, dark-lighted condition, dark-unlighted condition, and commercial areas. Using the same data, Ulfarsson et al. [16] explored the fault assignment of pedestrian-motor vehicle crashes in NC. Drivers were found to be at fault in their maneuvering acts (e.g., turning, backing, merging) while pedestrians were at fault in cases where they were unattentively crossing streets or walking along the streets. Both pedestrians and drivers were found to be at fault in cases of intoxication and in poorly lit environments.

Islam and Jones [8] analyzed injury severity of highway patrol reported pedestrian at-fault crash data from 2006 to 2010 in Alabama. They found that the contributing factors differ in different locations: urban location (e.g., female, pedestrian age, crash location, day of the week, winter and summer season) and rural location (e.g., pedestrian age). Contributing factors not affected by locations were dark-lighted conditions, two-lane roadways, and pedestrian of 12 years of age or younger. Ballesteros et al. [5] studied the association of pedestrian injury with vehicle type by combining data from highway patrol reported crash, trauma registry, and autopsy data from 1995 to 1999 in Maryland. The study found that SUV and pick-up trucks have a higher contribution to injury severity than others. Moudon et al. [13] examined the pedestrian injury severity using crash data on state routes from years 1999 to 2004 and city streets from years 2000 to 2004 in King County, Washington. The contributing factors of injury severity for state routes include older pedestrian, intersections without signals, vehicle speed while in city routes, middle-aged and younger pedestrian, and number of residential streets. Zajac and Ivan [17] investigated the injury severity of pedestrian crashes in rural Connecticut using 1989 to 1998 data from the Connecticut Department of Transportation. They found that the factors that influence injury severities were older and intoxicated pedestrian, intoxicated drivers, vehicle type, village, downtown fringe, and low-density residential area.

All of the aforementioned studies found influencing factors for injury severity of pedestrians using data from different states in the U.S. These studies used various explanatory variables, data sources, and methodological techniques for the investigation of the crash data. Due to the ordinal nature of the injury severity (i.e., fatality, disabling injury, evident injury, possible injury, and no injury), this study uses an ordered probit model to analyze single-vehicle, single-pedestrian crash data in Ohio. Furthermore, underreporting of crashes and injury severity levels of pedestrians is not uncommon in the highway patrol reported crash databases. To address this unobserved heterogeneity issue, the standard fixed-parameters ordered probit model is also extended to include random parameters in the model specification. Additionally, average direct pseudo-elasticities of the estimated parameters are computed to determine the impact of factors on the likelihood of each injury severity level. 


\section{Materials and Methods}

The data used in this study, extracted from the Highway Safety Information System database, consist of five years of single-vehicle, single-pedestrian crash records (2009 to 2013) in the state of Ohio. After eliminating the crash observations with missing data in variables, a total of 3184 observations of pedestrian injury severity were considered in the final dataset for model estimation. Each observation records the injury severity of the pedestrian involved in the crash, along with pedestrian, driver, vehicle, crash, and roadway characteristics. The final dataset consisted of 211 (6.6 percent) fatality, 749 (23.5 percent) disabling injury, 1212 (38.1 percent) evident injury, 738 (23.2 percent) possible injury, and 274 (8.6 percent) cases of no injury to the pedestrians. To ensure sufficient observation in each injury severity level, following the approach used by other researchers $[8,18,19]$, the five injury severity levels were consolidated into three levels-major injury (fatality and disabling injury), minor injury (evident injury), and possible/no injury (possible and no injury). Hence, the dependent variable is the injury severity of a pedestrian from a single-vehicle crash where the severity could be major, minor, or possible/no injury. The data analysis was started with univariate analysis [20]. Table 1 presents the descriptive statistics of the explanatory variables (i.e., crash factors) considered in this study. All the variables are indicator variables (with values 0 and 1 ) and the mean values represent the proportion of the variables. The mean value of the variable "day of week" is 0.793 , meaning that $79.3 \%$ of the pedestrians were involved in crashes during weekdays and $20.7 \%$ of the pedestrians were involved in crashes on weekends.

Due to the ordered nature of the crash injury severity level, several researchers used the ordered logit/probit models to examine the relationship between crash factors and injury severity outcomes $[15,19,21]$. With this in mind, this study models the pedestrian injury severity as follows: 0 for major injury, 1 for minor injury, 2 for possible/no injury. The dependent variable $y^{*}$ is specified as follows, which is a latent and continuous measure of pedestrian injury severity of each observation $n[22]$.

$$
y^{*}=\beta X+\epsilon
$$

where $\beta$ = vector of crash parameters to be estimated, $X=$ vector of explanatory variables (e.g., pedestrian, driver, vehicle, crash, and roadway characteristics), and $\epsilon=$ random error term, which is assumed to be normally distributed with a mean of 0 and a variance of 1 .

The observed injury severity data $y$ for each observation $n$ can be represented as follows under the probit modeling framework and by using Equation (1) [22].

$$
\begin{gathered}
y=0 \text { if }-\infty \leq y^{*} \leq \mu_{0} \\
y=1 \text { if } \mu_{0} \leq y^{*} \leq \mu_{1} \\
y=2 \text { if } \mu_{1} \leq y^{*} \leq \infty
\end{gathered}
$$

where $\mu=$ parameters or thresholds to be estimated between two adjacent injury severity levels that define $y$.

The ordered probit model is defined as follows [22].

$$
\begin{aligned}
& P_{n}(y=0)=\Phi(-\boldsymbol{\beta} \boldsymbol{X}) \\
& P_{n}(y=1)=\Phi\left(\mu_{1}-\boldsymbol{\beta} \boldsymbol{X}\right)-\Phi(-\boldsymbol{\beta} \boldsymbol{X}) \\
& P_{n}(y=2)=1-\Phi\left(\mu_{1}-\boldsymbol{\beta} \boldsymbol{X}\right)
\end{aligned}
$$

where $P_{n}(y=0)$ is the probability that observation $n$ has the least order of injury severity (i.e., major injury) given a crash occurred and $\Phi(\cdot)=$ standard normal cumulative distribution function.

To account for the unobserved heterogeneity, the fixed-parameters ordered probit model is extended to include random-parameters as follows [23], where error term is correlated with the unobserved factors in $\epsilon$.

$$
\beta_{k}=\beta+\gamma_{k}
$$


where $\gamma_{k}=$ randomly distributed term (e.g., normal, lognormal, triangular) corresponding to $k$-th explanatory variable. The random-parameters estimation is done using the Halton sequence approach and maximizing the simulated log-likelihood function [18,19].

Table 1. Descriptive statistics of the explanatory variables.

\begin{tabular}{|c|c|c|}
\hline Explanatory Variable & Mean & SD \\
\hline \multicolumn{3}{|l|}{ Pedestrian Characteristics } \\
\hline \multicolumn{3}{|l|}{ Age } \\
\hline Less than 18 ( 1 if less than 18 years old; 0 otherwise) & 0.225 & 0.417 \\
\hline 18-24 ( 1 if between 18 and 24 years; 0 otherwise) & 0.156 & 0.363 \\
\hline $25-54$ ( 1 if between 25 and 54 years; 0 otherwise) & 0.427 & 0.495 \\
\hline $55-64$ ( 1 if between 55 and 64 years; 0 otherwise) & 0.104 & 0.305 \\
\hline Over 65 ( 1 if over 65 years; 0 otherwise) & 0.088 & 0.284 \\
\hline Gender ( 1 if female; 0 otherwise) & 0.415 & 0.493 \\
\hline \multicolumn{3}{|l|}{ Driver Characteristics } \\
\hline \multicolumn{3}{|l|}{ Age } \\
\hline Less than 24 ( 1 if less than 24 years old; 0 otherwise) & 0.190 & 0.393 \\
\hline $25-54$ ( 1 if between 25 and 54 years; 0 otherwise) & 0.526 & 0.499 \\
\hline $55-64$ ( 1 if between 55 and 64 years; 0 otherwise) & 0.147 & 0.354 \\
\hline Over 65 ( 1 if over 65 years; 0 otherwise) & 0.137 & 0.344 \\
\hline Gender ( 1 if female; 0 otherwise) & 0.437 & 0.496 \\
\hline DUI driving ( 1 if yes; 0 otherwise) & 0.074 & 0.261 \\
\hline Restraint use ( 1 if seat belt; 0 otherwise) & 0.868 & 0.338 \\
\hline \multicolumn{3}{|l|}{ Vehicle Type } \\
\hline Passenger car (1 if passenger car; 0 otherwise) & 0.549 & 0.498 \\
\hline Truck ( 1 if truck; 0 otherwise) & 0.048 & 0.213 \\
\hline Minivan (1 if minivan; 0 otherwise) & 0.064 & 0.245 \\
\hline Sport-utility vehicle (SUV) (1 if SUV; 0 otherwise) & 0.178 & 0.393 \\
\hline Pickup truck ( 1 if pickup truck; 0 otherwise) & 0.127 & 0.332 \\
\hline \multicolumn{3}{|l|}{ Crash Characteristics } \\
\hline Crash location ( 1 if urban; 0 otherwise) & 0.875 & 0.331 \\
\hline \multicolumn{3}{|l|}{ Time of day } \\
\hline 7 a.m.-9:59 a.m. (1 if between 7 a.m. and 10 a.m.; 0 otherwise) & 0.119 & 0.324 \\
\hline 10 a.m.-3:59 p.m. ( 1 if between 10 a.m. and 4 p.m.; 0 otherwise $)$ & 0.302 & 0.459 \\
\hline 4 p.m.-6:59 p.m. (1 if between 4 p.m. and 7 p.m.; 0 otherwise) & 0.227 & 0.418 \\
\hline 7 p.m.-6:59 a.m. ( 1 if between 7 p.m. and 7 a.m.; 0 otherwise) & 0.352 & 0.478 \\
\hline Day of week (1 if weekday; 0 otherwise) & 0.793 & 0.405 \\
\hline \multicolumn{3}{|l|}{ Lighting Condition } \\
\hline Daylight ( 1 if daylight; 0 otherwise) & 0.557 & 0.497 \\
\hline Dark-unlighted ( 1 if dark without street light; 0 otherwise) & 0.117 & 0.321 \\
\hline Dark-lighted (1 if dark with street light; 0 otherwise) & 0.268 & 0.443 \\
\hline Weather condition ( 1 if adverse weather; 0 otherwise) & 0.176 & 0.381 \\
\hline \multicolumn{3}{|l|}{ Roadway Characteristics } \\
\hline \multicolumn{3}{|l|}{ Number of lanes } \\
\hline Two lanes ( 1 if two lanes roadway; 0 otherwise) & 0.290 & 0.454 \\
\hline Four lanes ( 1 if four lanes roadway; 0 otherwise) & 0.585 & 0.493 \\
\hline Six lanes ( 1 if six lanes roadway; 0 otherwise) & 0.087 & 0.282 \\
\hline \multicolumn{3}{|l|}{ Speed limit } \\
\hline$\leq 35 \mathrm{mph}$ ( 1 if $\leq 35 \mathrm{mph}$ roadway; 0 otherwise) & 0.698 & 0.459 \\
\hline $40 \mathrm{mph}$ ( 1 if $40 \mathrm{mph}$ roadway; 0 otherwise) & 0.113 & 0.317 \\
\hline $50 \mathrm{mph}$ ( 1 if $50 \mathrm{mph}$ roadway; 0 otherwise) & 0.121 & 0.326 \\
\hline$\geq 60 \mathrm{mph}$ ( 1 if $\geq 60 \mathrm{mph}$ roadway; 0 otherwise) & 0.068 & 0.251 \\
\hline
\end{tabular}

SD: standard deviation; DUI: driving under influence. 
To estimate the impact of variables on the likelihood of each injury severity level, elasticities are often used. For a binary indicator variable (has value 0 or 1), the direct pseudo-elasticities are computed as follows [9], which measures the change in estimated probability percentage of injury severity when the dummy variable is switched between 0 and 1 .

$$
E_{X_{\text {ink }}}^{P_{\text {in }}}=\frac{P_{\text {in }}\left[\text { given } X_{i n k}=1\right]-P_{\text {in }}\left[\text { given } X_{\text {ink }}=0\right]}{P_{\text {in }}\left[\text { given } X_{\text {ink }}=0\right]}
$$

where $P_{i n}=$ probability of injury severity level $i$ for observation $n$ as defined in Equation (3) and $X_{i n k}$ is the $k$-th explanatory variable associated with injury severity level $i$ for observation $n$.

\section{Results and Discussion}

To validate the crash data, a two-thirds random sample was generated from the master dataset. The injury severity was selected for strata so that the proper proportioning was ensured. A random-parameters ordered probit model was then estimated using the two-thirds sample. Then the model was compared using the holdout sample (i.e., remaining one-third sample). It was found that the coefficients decreased relative to the population size. That means the dataset is valid for the modeling approach [24].

A fixed-parameters ordered probit model was estimated using the maximum likelihood method and a random-parameters ordered probit model was estimated using the simulated maximum likelihood method. Five hundred Halton draws were used, and it was assumed that random parameters were normally distributed. The variables in both models were included in the model specifications when they were statistically significant at the $90 \%$ confidence level. Furthermore, to avoid the inclusion of highly correlated variables in the model, a correlation matrix was estimated, and the results indicate that none of the variables have a correlation value of more than $\pm 0.20[19,25]$. In addition, the Variance Inflation Factor (VIF) values were estimated for all explanatory variables. The VIF values were less 10, which suggests that there is no need to concern about multicollinearity in the model. Table 2 presents the model estimation results along with the average direct pseudo-elasticity values. Note that elasticity values are calculated from the random-parameters model results. A likelihood ratio test was performed, following the methodology articulated in Washington et al. [22], to compare the fixed- and random-parameters models.

$$
\chi^{2}=-2\left[L L_{f}\left(\beta^{f}\right)-L L_{r}\left(\beta^{r}\right)\right]
$$

where $L L_{f}\left(\beta^{f}\right)=$ log-likelihood at the convergence of the fixed-parameters model $(-3336.07)$ and $L L_{r}\left(\beta^{r}\right)=\log$-likelihood at the convergence of the random-parameters model (-3318.15). The Chi-square test statistic with seven degrees of freedom resulted in a value greater than the $99.99 \%$ confidence limit, which indicates the validity of the random-parameters model over the corresponding fixed-parameters model. Seven parameters, older pedestrian, older driver, driving under influence (DUI), truck, urban location, dark-unlighted condition, and six lane roadways, were found to be random with statistically significant standard deviations at the $90 \%$ confidence level.

With regard to the pedestrian characteristics, only older pedestrian (age 65 and over) was found to be statically significant. The parameter is random and is normally distributed with mean -0.39 and standard deviation of 1.00. Given these values, 65.2 percent of the observations have parameter values less than 0 and 34.8 percent greater than 0 . For the majority of the observations, older pedestrians were found to be involved in more severe injuries. The elasticities demonstrated a 43.1 percent increase in major injuries, 5.1 percent decrease in minor injuries, and 59.4 percent decrease in possible/no injuries for older pedestrians. One possible explanation could be the fact that the older individuals may have less injury sustaining capabilities. Kim et al. $[9,10]$ also found that with the increase in pedestrian age the probability of sustaining severe injury increases.

As for the driver characteristics, younger driver (less than 24), older driver (65 and over), and driving under influence (DUI) were found to be statistically significant. It was determined that when a 
pedestrian is struck by a young driver, the probability of major injuries sustained by the pedestrian increases by 18.9 percent. Conversely, the driver being older decreased the probability of major injuries by 21.1 percent. This may be because older drivers are more cautious while driving compared to young drivers as well as the tendency for older drivers to drive more on lower speed roads. The older driver variable was found to be random and normally distributed with mean 0.23 and standard deviation 1.03. With these estimates, 41.5 percent of the observations have parameter values less than 0 and 58.5 percent have parameter values greater than 0 . This implies that slightly less than half of the observations result in severe injuries to pedestrians and slightly more than half result in less severe injuries. The variable DUI was found to be random and normally distributed with mean -0.80 and standard deviation 1.07. The estimates suggest that for 77.3 percent of the observations the parameter values were less than 0 . That means that for the majority of the cases where the driver was intoxicated, more severe injuries were inflicted upon the pedestrians. Specifically, intoxicated drivers were found to increase the probability of major injuries by 95.2 percent. This effect is the highest among all of the variables.

Table 2. Parameter estimates and elasticities.

\begin{tabular}{|c|c|c|c|c|c|}
\hline \multirow[b]{2}{*}{ Explanatory Variable } & \multicolumn{2}{|c|}{ Parameter Estimates } & \multicolumn{3}{|c|}{ Average Direct Pseudo-Elasticities $\ddagger$} \\
\hline & $\begin{array}{c}\text { Fixed-Parameters } \\
\text { Model }\end{array}$ & $\begin{array}{c}\text { Random-Parameters } \\
\text { Model }\end{array}$ & $\begin{array}{l}\text { Major } \\
\text { Injury }\end{array}$ & $\begin{array}{l}\text { Minor } \\
\text { Injury }\end{array}$ & $\begin{array}{l}\text { Possible/No } \\
\text { Injury }\end{array}$ \\
\hline \multicolumn{6}{|c|}{ Pedestrian Characteristics } \\
\hline Over 65 & $-0.27^{* * *}$ & $-0.39^{* * *}\left(1.00^{* * *}\right)^{\dagger}$ & $43.1 \%$ & $-5.1 \%$ & $-59.4 \%$ \\
\hline \multicolumn{6}{|c|}{ Driver Characteristics } \\
\hline Less than 24 & $-0.12 * *$ & $-0.18 * * *$ & $18.9 \%$ & $-0.8 \%$ & $-30.5 \%$ \\
\hline Over 65 & $0.12 * *$ & $0.23^{* * *}\left(1.03^{* * *}\right)^{\dagger}$ & $-21.1 \%$ & $-1.7 \%$ & $41.9 \%$ \\
\hline DUI driving & $-0.45^{* * *}$ & $-0.80^{* * *}\left(1.07^{* * *}\right)^{\dagger}$ & $95.2 \%$ & $-20.5 \%$ & $-102.2 \%$ \\
\hline \multicolumn{6}{|c|}{ Vehicle Type } \\
\hline Passenger car & $0.07 *$ & $0.08 *$ & $-8.1 \%$ & $-0.1 \%$ & $14.1 \%$ \\
\hline Truck & $-0.29 * * *$ & $-0.49^{* * *}\left(0.77^{* * *}\right)^{\dagger}$ & $55.9 \%$ & $-8.7 \%$ & $-70.5 \%$ \\
\hline \multicolumn{6}{|c|}{ Crash Characteristics } \\
\hline Crash location & $0.16^{* *}$ & $0.26^{* * *}\left(0.89^{* * *}\right)^{+}$ & $-27.4 \%$ & $2.0 \%$ & $41.5 \%$ \\
\hline 10 a.m. to $3: 59$ p.m. & $0.17^{* * *}$ & $0.24^{* * *}$ & $-23.0 \%$ & $-1.1 \%$ & $43.4 \%$ \\
\hline Day of week & $0.12 * *$ & $0.17^{* * *}$ & $-17.5 \%$ & $0.6 \%$ & $28.4 \%$ \\
\hline Daylight & $0.09 *$ & $0.12 * *$ & $-12.0 \%$ & $0.1 \%$ & $20.8 \%$ \\
\hline Dark-unlighted & $-0.29 * * *$ & $-0.50^{* * *}\left(1.10^{* * *}\right)^{\dagger}$ & $56.4 \%$ & $-7.7 \%$ & $-74.3 \%$ \\
\hline \multicolumn{6}{|c|}{ Roadway Characteristics } \\
\hline Six lanes & $-0.13 *$ & $-0.17^{* *}\left(0.85^{* * *}\right)^{\dagger}$ & $18.2 \%$ & $-1.0 \%$ & $-28.7 \%$ \\
\hline $40 \mathrm{mph}$ & $-0.24 * * *$ & $-0.36^{* * *}$ & $39.3 \%$ & $-4.0 \%$ & $-55.9 \%$ \\
\hline $50 \mathrm{mph}$ & $-0.37^{* * *}$ & $-0.55^{* * *}$ & $62.3 \%$ & $-9.1 \%$ & $-80.2 \%$ \\
\hline Constant & $0.36^{* * *}$ & $0.52 * * *$ & & & \\
\hline Threshold $1, \mu_{1}$ & $1.05^{* * *}$ & $1.52 * * *$ & & & \\
\hline Log-likelihood at zero, $L L(0)$ & -3481.60 & -3481.60 & & & \\
\hline Log-likelihood at convergence, $L L(\beta)$ & -3336.07 & -3318.15 & & & \\
\hline Akaike information criterion (AIC) & 6704.1 & 6682.3 & & & \\
\hline Number of observations & 3184 & 3184 & & & \\
\hline
\end{tabular}

In terms of the vehicle type, the analysis results showed that passenger car and truck were statistically significant factors. Being struck by a passenger car was found to decrease the likelihood of major injuries by 8.1 percent and increase the likelihood of possible/no injuries by 14.1 percent. The variable "truck" was found to be random and normally distributed with mean -0.49 and standard deviation of 0.77 . This indicates that for 73.8 percent of the observations involving a truck the pedestrians experienced more severe injuries, whereas 26.2 percent of pedestrians experienced less severe injuries. Furthermore, being struck by a truck was found to increase the likelihood of major injuries by 55.9 percent and decrease the likelihood of possible/no injuries by 70.5 percent. Trucks are 
heavier than other vehicle types, which leads to greater momentum and consequently more severe injuries. Similar results have been reported in the works by Abdul-Aziz et al. [3], Kim et al. [9,10], and Lee and Abdel-Aty [11].

With respect to the crash characteristics, crash location, crash time and day, and lighting condition were found to be statistically significant. Crashes occurring in urban locations were found to be random and normally distributed with mean 0.26 and standard deviation 0.89 . This implies that 38.5 percent of the observations have parameter values less than 0 and 61.5 percent greater than 0 . The majority of the observations had less severe injuries to the pedestrians when the crash occurred in urban locations. Specifically, crash in urban locations is associated with a lower likelihood of major injuries (27.4 percent) and a higher likelihood of possible/no injuries (41.5 percent) compared to that of rural locations. One possible explanation could be the fact that emergency response times are faster in urban areas. When pedestrian-vehicle crashes occurred between 10 a.m. and 3:59 p.m. (daytime traffic volume off-peak), the likelihood of major injuries decreased by 23.0 percent and the likelihood of possible/no injuries increased by 43.4 percent. This may be due to the lower traffic during the off-peak hour and consequently lower chance of being involved in crashes in general. Crashes that occurred during weekdays were found to decrease the likelihood of major injuries by 17.5 percent and increase the likelihood of possible/no injuries by 28.4 percent. Typically, during weekdays traffic volume is higher than weekends, which in turn results in lower travel speed. Hence, the risk of a pedestrian being involved in a high speed impact reduces and consequently the chance of major injuries decreases. The findings from the analysis for lighting condition variables are intuitive. The elasticity results indicate that the probability of major injuries was found to decrease under daylight condition (12.0 percent), whereas the probability of major injuries was found to increase under dark-unlighted condition (56.4 percent). Under dark conditions, roadway visibility is lower, which may lead to more severe injuries to the pedestrians. These findings related to lighting variable are consistent to those of prior pedestrian-vehicle safety studies $[3,8-10,16]$. Furthermore, the parameter for the dark-unlighted condition was found to be random and normally distributed with mean -0.50 and standard deviation 1.10. Given these estimates, 67.5 percent of the observations under dark-unlighted conditions were found to be involved in more severe injuries and 32.5 percent in less severe injuries.

As for the roadway characteristics, six-lane roadways and speed limits being $40 \mathrm{mph}$ and $50 \mathrm{mph}$ were found to be significant in explaining pedestrian-vehicle crash injury severity. The variable indicating six-lane roadways was found to be random and normally distributed with mean -0.17 and standard deviation 0.85 . This indicates that slightly more than half of the observations ( 57.9 percent) where crashes occurred on six-lane roadways experienced more severe injuries and slightly less than half experienced less severe injuries. The probability of major injuries sustained by pedestrians was found to increase by 18.2 percent when crashes occurred on six-lane roadways and the probability of possible/no injuries was found to decrease by 28.7 percent. A possible reason could be the fact that six-lane roadways carry higher traffic; hence, the chance of pedestrians being involved in crashes increases. In terms of the speed limit, higher speed was found to increase the likelihood of major injuries: 39.3 percent in cases of $40 \mathrm{mph}$ and 62.3 percent in cases of $50 \mathrm{mph}$. These findings are reasonable, since higher speed impacts result in more severe injuries.

In summary, this study is the first to use both fixed- and random-parameters ordered probit modeling approaches to consider pedestrian vehicle crash data in a U.S. state. It investigated the crash factors and determined which factors are influencing injury severity of pedestrians from motor vehicles crashes, specifically for crashes occurring in the state of Ohio. As evident from Tables 1 and 2, some of the variables were found not to be significant in explaining the injury severity. However, some of those variables were found to be significant by other studies from different U.S. states. For instance, Kim et al. [9] found that in North Carolina male pedestrians are 1.2 times more vulnerable to major injuries compared to female pedestrians. Islam and Jones [8] demonstrated that in Alabama female pedestrians are about 3 percent more likely to be involved in major injuries compared to their male counterparts. Conversely, Pour-Rouholamin and Zhou [14] found that pedestrian gender is 
not significant for the injury severity in Illinois. This study found the pedestrian gender to not be significantly related to the injury severity in Ohio. A similar pattern is present among the studies for considering cases involving SUVs. This current study did not find SUVs to be significant in explaining injury severity. Lee and Abdel-Aty [11] reported a similar finding for pedestrians in Florida. However, Ballesteros et al. [5] indicated that SUVs were associated with more severe injuries in Maryland. Pour-Rouholamin and Zhou [14] reported that SUVs increase the probability of being involved in severe injuries by 8.6 percent. The abovementioned findings further validate the disaggregated nature of pedestrian vehicle crash data analysis in Ohio.

\section{Conclusions and Recommendations}

This study employed fixed- and random-parameters ordered probit models to analyze pedestrian, driver, vehicle, crash, and roadway factors associated with the injury severity of pedestrians from pedestrian-vehicle crashes in the state of Ohio using crash data from 2009 to 2013. The injury severity of pedestrians was defined as major injury, minor injury, and possible/no injury. Likelihood ratio testing suggested that the use of random-parameters model is appropriate for investigating pedestrian crash data due to the unobserved heterogeneity (i.e., unobserved factors) coming from the underreporting of the pedestrian severity level. It was found from the analysis that older pedestrian ( 65 and over), younger driver (less than 24), driving under influence (DUI), being struck by truck, dark-unlighted roadways, six-lane roadways, and speed limits of $40 \mathrm{mph}$ and $50 \mathrm{mph}$ were factors that were associated with more severe injuries to the pedestrians. In contrast, older driver (65 and over), passenger car, crash occurring in urban locations, daytime traffic off-peak (10 a.m. to 3:59 p.m.), weekdays, and daylight condition were factors associated with less severe injuries. The method and findings from the study could help policy makers in state departments of transportation to identify critical crash factors and to develop safety countermeasures to reduce pedestrian injuries.

Based on the findings, a number of practical policy implications can be made. First, it is recommended that marked crosswalks along with a traffic signal or stop sign should be used where older pedestrian crashes are higher [26]. These older pedestrians need special attention since in the period from 2000 to 2010 the population aged 65 and over in Ohio increased by 7.6 percent [27]. Second, for young drivers, stricter traffic rules and regulations could be enforced. Third, driver intoxication was found to be the factor having the highest effect on pedestrian injury severity and the probability of major injuries increased by about 73 percent when the driver hitting the pedestrian was intoxicated. Hence, it is highly recommended that stricter rules and fines should be enforced in cases of DUI. Fourth, the impact of a pedestrian being hit by a heavier vehicle is significantly higher than that of a passenger car. Hence, based on the number of the pedestrian fatalities and injuries caused by trucks, local and state authorities may consider restricting truck traffic from certain segments of the roadways with high pedestrian activities and during peak pedestrian hours. Fifth, our analysis revealed that lighting had an observed effect on pedestrian injury severity, whereby daylight condition was associated with less severe injuries and dark condition was associated with more severe injuries. Hence, it is recommended that the level of lighting should be increased (i.e., installing street lights) at roadway segments where the chance of pedestrian crashes is higher during nighttime. Sixth, the probability of a pedestrian sustaining more severe injury was higher from crashes occurring on six-lane roadways. Having six lanes in a roadway segment implies longer crossing distance for pedestrians and higher traffic volumes. It is recommended that pedestrian signals should be installed in cases where there is high pedestrian volume. Also, grade-separated pedestrian crossings could be installed. Lastly, pedestrian-vehicle crashes occurring in areas having higher traffic speed limit were found to increase the probability of a pedestrian being involved in major injuries. In areas with high pedestrian activities and with crash history, as a safety countermeasure, speed limits could be reduced.

Author Contributions: Both authors performed all the tasks equally in regard to the data analyses and the writing of the paper. 
Acknowledgments: The authors acknowledge the Highway Safety Information System Laboratory for their help in providing data for this study.

Conflicts of Interest: There is no conflict of interest.

\section{References}

1. National Highway Traffic Safety Administration. Traffic Safety Facts 2015 Data. Available online: Crashstats. nhtsa.dot.gov/Api/Public/ViewPublication/812375 (accessed on 5 March 2018).

2. Bureau of Transportation Statistics. Transportation Fatalities by Mode. Available online: https://www.bts. gov/content/transportation-fatalities-mode (accessed on 5 March 2018).

3. Abdul-Aziz, H.M.; Ukkusuri, S.V.; Hasan, S. Exploring the determinants of pedestrian-vehicle crash severity in New York City. Accid. Anal. Prev. 2010, 50, 1298-1309. [CrossRef] [PubMed]

4. Anderson, R.W.G.; McLean, A.J.; Farmer, M.J.B.; Lee, B.H.; Brooks, C.G. Vehicle travel speeds and the incidence of fatal pedestrian crashes. Accid. Anal. Prev. 1997, 29, 667-674. [CrossRef]

5. Ballesteros, M.F.; Dischinger, P.C.; Langenberg, P. Pedestrian injuries and vehicle type in Maryland, $1995-1999$. Accid. Anal. Prev. 2004, 36, 73-81. [CrossRef]

6. Davis, G. Relating severity of pedestrian injury to impact speed in vehicle-pedestrian crashes: Simple threshold model. Transp. Res. Rec. 2010, 1773, 108-113. [CrossRef]

7. Garder, P.E. The impact of speed and other variables on pedestrian safety in Maine. Accid. Anal. Prev. 2004, 36, 533-542. [CrossRef]

8. Islam, S.; Jones, S.L. Pedestrian at-fault crashes on rural and urban roadways in Alabama. Accid. Anal. Prev. 2014, 72, 267-276. [CrossRef] [PubMed]

9. Kim, J.-K.; Ulfarsson, G.F.; Shankar, V.N.; Kim, S. Age and pedestrian injury severity in motor-vehicle crashes: A heteroskedastic logit analysis. Accid. Anal. Prev. 2008, 40, 1695-1702. [CrossRef] [PubMed]

10. Kim, J.-K.; Ulfarsson, G.F.; Shankar, V.N.; Mannering, F.L. A note on modeling pedestrian injury severity in motor vehicle crashes with the mixed logit model. Accid. Anal. Prev. 2010, 42, 1751-1758. [CrossRef] [PubMed]

11. Lee, C.; Abdel-Aty, M. Comprehensive analysis of vehicle-pedestrian crashes at intersections in Florida. Accid. Anal. Prev. 2005, 37, 775-786. [CrossRef] [PubMed]

12. Matsui, Y. Effects of vehicle bumper height and impact velocity on type of lower extremity injury in vehicle-pedestrian accidents. Accid. Anal. Prev. 2005, 37, 633-640. [CrossRef] [PubMed]

13. Moudon, A.V.; Lin, L.; Jiao, J.; Hurvitz, P.; Reeves, P. The risk of pedestrian injury and fatality in collisions with motor vehicles, a social ecological study of state routes and city streets in king county, Washington. Accid. Anal. Prev. 2011, 43, 11-24. [CrossRef] [PubMed]

14. Pour-Rouholamin, M.; Zhou, H. Investigating the risk factors associated with pedestrian injury severity in Illinois. J. Saf. Res. 2016, 57, 9-17. [CrossRef] [PubMed]

15. Sasidharan, L.; Menedez, M. Partial proportional odds model-An alternate choice for analyzing pedestrian crash injury severities. Accid. Anal. Prev. 2014, 72, 330-340. [CrossRef] [PubMed]

16. Ulfarsson, G.F.; Kim, S.; Booth, K.M. Analyzing fault in pedestrian-motor vehicle crashes in North Carolina. Accid. Anal. Prev. 2010, 42, 1805-1813. [CrossRef] [PubMed]

17. Zajac, S.S.; Ivan, J.N. Factors influencing injury severity of motor vehicle-crossing pedestrian crashes in rural Connecticut. Accid. Anal. Prev. 2003, 35, 369-379. [CrossRef]

18. Uddin, M.; Huynh, N. Truck-involved crashes injury severity analysis for different lighting conditions on rural and urban roadways. Accid. Anal. Prev. 2017, 108, 44-55. [CrossRef] [PubMed]

19. Uddin, M.; Huynh, N. Factors influencing injury severity of crashes involving HAZMAT trucks. Int. J. Transp. Sci. Technol. 2018, 7, 1-9. [CrossRef]

20. Huynh, N.; Uddin, M.; Minh, C.C. Data analytics for intermodal freight transportation applications. In Data Analytics for Intelligent Transportation Systems, 1st ed.; Chowdhury, M., Apon, A., Dey, K., Eds.; Elsevier Science: Cambridge, MA, USA, 2017; Chapter 10, pp. 241-262. ISBN 9780128097151. [CrossRef]

21. Abdel-Aty, M. Analysis of driver injury severity levels at multiple locations using ordered probit models. J. Saf. Res. 2003, 34, 597-603. [CrossRef]

22. Washington, S.P.; Karlaftis, M.G.; Mannering, F.L. Statistical and Econometric Methods for Transportation Data Analysis, 2nd ed.; Chapman \& Hall/CRC: Boca Raton, FL, USA, 2011; ISBN 9781420082852. 
23. Greene, W. Econometric Analysis, 3rd ed.; Macmillan: New York, NY, USA, 1997; ISBN 9780023466021.

24. Anderson, J.; Hernandez, S. Roadway classifications and the accident injury severities of heavy-vehicle drivers. Anal. Methods Accid. Res. 2017, 15, 17-28. [CrossRef]

25. Pai, C.-W.; Saleh, W. Modelling motorcyclist injury severity by various crash types at T-junctions in the UK. Saf. Sci. 2008, 46, 1234-1247. [CrossRef]

26. Koepsell, T.; McCloskey, L.; Wolf, M.; Moudon, A.V.; Buchner, D.; Kraus, J.; Patternson, M. Crosswalk markings and the risk of pedestrian-motor vehicle collisions in older pedestrians. JAMA 2002, 288, 2136-2143. [CrossRef] [PubMed]

27. U.S. Census Bureau. The Older Population: 2010. Available online: https://www.census.gov/prod/ cen2010/briefs/c2010br-09.pdf (accessed on 5 March 2018).

2018 by the authors. Licensee MDPI, Basel, Switzerland. This article is an open access article distributed under the terms and conditions of the Creative Commons Attribution (CC BY) license (http:/ / creativecommons.org/licenses/by/4.0/). 